a convivência competitiva de três sistemas de crenças e práticas de saúde. Da mesma forma, o artigo de G. B. Fosu ("Perceptions of mental disorders in the context of social change") sublinha a interpenetração de diferentes códigos interpretativos dos distúrbios mentais.

Esta revista vale a pena ser lida por vários motivos: pelas questões substantivas que abor- da, pelos temas apropriados aos antropólogos enquanto profissionais e seu mercado de trabalho, mas, sobretudo, pela relevância das abordagens conceituais que os artigos suscitam.

Maria Cecília de Souza Minayo Escola Nacional de Saúde Pública/Fiocruz

\section{Drum and Stethoscope: Integrating Ethnomedicine and Biomedicine in Bolivia.} Joseph W. Bastien. Salt Lake City: University of Utah Press, 1992. 266 p., ilus., biblio.

(Brochura)

ISBN 0-87480-386-1

US\$ 34.95

Throughout South America, biomedical resources - physicians, trained nurses, laboratories, hospitals with modern equipment - are concentrated in the larger centers, while rural areas, which are often remote and difficult to reach, lack even the most basic facilities for primary health care. Moreover, even in the cities, because of rapidly increasing population, health care is spread thin, and the best of it is only accessible to the middle and upper classes.

In this book Bastien argues that, in relying exclusively on biomedicine to provide for the primary health care needs of developing countries, policy makers are neglecting the potential contributions that traditional healers, herbalists, ritual practitioners, and midwives could make to an integrated system of health care. He points out that in Bolivia there is "at least one midwife, shaman, and herbalist for every rural community with a population ranging from 200 to 1,000 in population, compared to one physician per 7,000 in population".

Bastien does not advocate that attempts to broaden the benefits of biomedicine should be abandoned. He believes that it is possible to integrate biomedicine and ethnomedicine in an economically and culturally appropriate system of health care that serves people better by preserving the advantages of both. Admittedly, this is not easy, for biomedicine and ethnomedicine represent philosophies of healing that are based on different premises. Doctors assume that the causative factors of disease are universal and can be discovered by scientific investigation. In contrast, ethnomedical systems vary by locality, since their healing practices are based on the traditions of a particular region and herbal medicines on locally available plants. Ethnomedical ideologies may include beliefs about the proper relations of people to one another and to the supernatural world, thus curing practices may aim at restoring balance in these relations through rituals prescribed by the healer. The interventions of traditional healers are often successful in restoring their patients' well-being because they are rooted in the culture and traditions that healer and patient share.

Over a number of years Bastien has studied the Kallawaya herbalists of highland Bolivia who maintain a tradition of healing with plants that goes back hundreds of years. According to Bastien these herbal specialists employ more than a thousand medicinal plants, of which 25 to $30 \%$ are effective according to measurements made by biomedical methods. Kallawaya herbalists, who travel widely over assigned trade routes, became renowned for their healing abilities throughout the Andean countries, and even in Europe. An aspiring herbalist would spend as long as 8 years in apprenticeship learning the art from a master healer before undertaking cures on his own. After a period during which herbalists were persecuted by the biomedical establishment, they have recently gained new respect, partly due to the current search for medicinal plants and the international revival of interest in herbal medicine. 
Since the Alma-Ata conference in 1978 WHO and UNICEF have advocated basing systems of primary health care in developing countries on community participation and the utilization of ethnomedicine. However, up to the present this model has seldom been implemented because of the resistance of biomedically trained doctors and nurses who see ethnomedicine as a "second-class system" rooted in superstition and a threat to their claim of exclusive authoritative knowledge. In Bastien's view, the successful implementation of a system that combines all the resources available to a rural community requires that both biomedical and ethnomedical practitioners learn to respect and acknowledge each other's areas of expertise.

"The approach to integration advocated within this book is one of articulation or a modified autonomy model. This model advocates maintaining the ethnoscience and cultural integrity of ethnomedicine and accommodating folk knowledge of its practitioners. This approach not only respects and recognizes the value of ethnomedicine as being linked to environmentally adaptive strategies, as well as deeply rooted beliefs, but also assists its practitioners in improving their therapeutic efforts with biomedical practices that are economically and environmentally adaptive, consonant with cultural beliefs, and sensitive to their experiences of illness. Articulation implies a culturally sensitive understanding of the ethnomedical system and its assumptions (body concepts, cosmology, etiology, and ethnopharmacology), practices, and ecology of the region to which it is adapted. Knowledge of these structural features is necessary in order to fit some technique from biomedicine into the system" (pp. 39-40).

In order to attain these goals, more research is needed into ecological and cultural features of ethnomedicine. Bastien points out that research in ethnomedicine should receive government support not only because it contributes to the health care of rural populations, but because it may also serve the national economy by testing the pharmacological properties of plant-based medicines that may effectively substitute expensive imported drugs. Not only can herbalists identify plants with therapeutic value, they can describe from firsthand experience the effects of the plants they prescribe.

Bolivia, with its strong traditions of herbal and ritual healing, the isolation, both geographic and cultural, of rural communities, and lack of economic resources to deliver modern medical technology to all its people, would seem to be an appropriate country to implement the integrated model that Bastien advocates. However, he is able to point only to isolated instances of true integration. Some herbalists have incorporated biomedical practices in their treatments, and a few doctors have collaborated with shamans and herbalists. A rural health program for the department of Oruro designed by a medical anthropologist and a rural health educator seems to have considerable success in training local people as community health workers. Some of these health promoters find themselves in opposition with traditional healers, but the Ministry of Health has encouraged the selection of ethnomedical practitioners for training as health promoters, and one-fourth of the promoters in the Oruro project practice ethnomedicine as midwives, herbalists, diviners, or shamans.

Medical anthropologists have found that when patients have a choice of biomedical and ethnomedical health care they often do not depend exclusively on either, but choose opportunisticaly, perhaps consulting both for the same complaint. It is left to the patient to "integrate" these separate and often competing tracks, sometimes inappropriately. At the level of the system, perhaps cooperation and mutual respect is a more attainable goal than integration. When a mysterious epidemic recently broke out on the Navajo reservation in Arizona, traditional healers were the first to draw a connection between the disease and increased rodent population following a mild, wet winter, and alerted researchers from the Center for Disease Control. The disease proved to be due to a hantavirus infection spread by rodents. While Navajo medicine men and biomedical researchers operate in separate spheres, the local ecological 
knowledge of the traditional healers was important in identifying the source of infection. While counseling caution and avoidance of rodents, the medicine men allayed the fears of the people by prescribing such curing rituals as the Squaw Dance or Enemy Way.

Drum and Stethoscope is a thoughtprovoking book, and should be required reading for public health professionals.
Bastien is a strong advocate for promoting respect for all those who work to preserve and improve people's health and well-being, whether by conventional biomedical or ethnomedical methods of healing.

Nancy M. Flowers Department of Anthropology, Hunter College City University of New York 